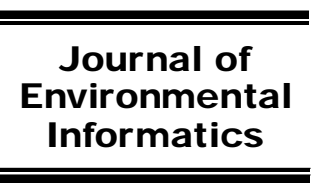

www.iseis.org/jei

\title{
The Use of Statistical Weather Generator, Hybrid Data Driven and System Dynamics Models for Water Resources Management under Climate Change
}

\author{
M. Amir Rahmani ${ }^{1}$, and M. Zarghami ${ }^{1,2, *}$ \\ ${ }^{I}$ Faculty of Civil Engineering, University of Tabriz, Tabriz 51664, Iran \\ ${ }^{2}$ Tufts Institute of the Environment, Tufts University, Medford, MA, 02155, USA
}

Received 2 September 2012; revised 5 January 2013; accepted 13 February, 2014; published online 6 December 2014

\begin{abstract}
Nowadays, the assumption of stationary patterns in hydrologic time series is being challenged, mainly because of climate change and the uncertainty brought about by it. In this paper, climate change and impacts on water resources of Zolachay in Urmia Lake basin in northwestern Iran have been studied comprehensively. Expected precipitation and temperature changes are obtained from the results of general circulation models (GCMs) approved by IPCC AR4 in three emission scenarios of A1B, A2, and B1. To simulate climate change conditions for horizon 2020, LARS-WG, as a stochastic weather generator, has been employed. Analyzing results by a Kernel density estimator indicates a decrease in annual precipitation and a tendency to a warmer climate. Then different data-driven models such as artificial neural network and M5 model tree, in conjunction with wavelet transform, have been used to develop a rainfall-runoff model of the basin on a monthly time scale. Results show that a warmer and drier climate in the future will cause the hydrograph to have temporal and quantitative changes. Operation of the multipurpose Zola Reservoir (located on the main stream) is simulated using the system dynamics approach. In addition to changes in the runoff of the basin, development scenario is also considered. Results demonstrate considerable changes in the reliability and deficiency measures in the operation of Zola Reservoir under climate change condition and development scenario. These results indicate that a revision in the rule curve of the reservoir is needed. Finally, this study predicts that more groundwater could be extracted to supply demands in the basin.
\end{abstract}

Keywords: impact of climate change, hybrid data driven models, system dynamics, reservoir operation, Urmia Lake

\section{Introduction}

Water scarcity threatens public welfare, economic development, and water-dependent ecosystems. However, climate change has important impacts on water resources, especially in semiarid regions. Bates et al., (2008) documented many scientific studies on impacts of global warming such as changes in precipitation patterns, intensity, and extremes; reduction in the snow cover and widespread melting of ice; and changes in soil moisture and runoff over the last few decades. With advances in development, meeting the increasing demand of water is becoming more challenging due to climate change (Vörösmarty et al., 2000). Population growth and its direct impact on water demand in Iran (Ardakanian, 2005), in addition to possible reduction in water availability, particularly in arid and semiarid basins (Wagener et al., 2010; Hoekstra et al., 2012; Sterling et al., 2013), may threaten sustainable development. Hence, an assessment of the impacts of climate change on water resources is crucial for determining the future possible challenges.

\footnotetext{
* Corresponding author. Tel.: +98 411 3392549; fax: +98 4113344287. E-mail address: mzarghami@tabrizu.ac.ir, zarghaami@gmail.com m.zarghami@tufts.edu (M. Zarghami).
}

ISSN: $1726-2135$ print/1684-8799 online

C) 2014 ISEIS All rights reserved. doi:10.3808/jei.201400285
General circulation models (GCMs) are the most current tools employed in climate change studies (Beyene et al., 2010; Bekele and Knap, 2010; Setegn et al., 2011; Zhang et al., 2011). Harma et al. (2012) developed climate change scenarios using two GCMs to predict water supply and demand in a basin located south of British Colombia. Raje and Mujumdar (2010) downscaled outputs of three GCMs to study the changes in inflow, operation, and power generation of a reservoir in future climate change condition in India. Barron et al. (2012) employed outputs of $15 \mathrm{GCMs}$ to assess the impacts of climate change on water resources and, consequently, the changes in water-dependent ecosystems in Southwestern Australia. According to their study, changes are not uniform throughout the region, but reductions in flow duration of rivers are likely to affect surface water-dependent ecosystems adversely. Also in the dry scenario, some groundwater-dependent ecosystems may also be affected. Montenegro and Ragab (2012) simulated the changes in land use and also in climate using two GCMs for a semiarid region in northeastern Brazil. Results show a decrease in water availability. In addition, climate change is likely to have more effect on water resources reduction than changes in land use.

The impact of climate change is more important in the water-scarce regions. The area of study in this research is selected from the Urmia Lake watershed in Iran. Urmia Lake, the second largest salty lake on the earth, is now drying up 
because of climate change and other factors (Abbaspour et al., 2012; Hassanzadeh et al., 2012). In recent studies, Abbaspour et al. (2009) investigated the impacts of climate change on water availability in Iran. They concluded that even precipitation is expected to increase in some parts of the country; in western parts of Urmia Lake, runoff may be reduced. Zarghami et al. (2011) studied the responses of runoff to climate change in three sub-basins flowing into Urmia Lake. Results indicate a considerable fall in the hydrograph of these sub-basins. Amir Rahmani and Zarghami (2013) simulated climate change in northwestern provinces of Iran using different GCMs. Results of their study indicate that, although changes in precipitation are not uniform across the region, temperature is likely to rise.

Employing GCMs in impact assessment studies is, however, a challenging issue. Coarse spatial resolution, missing subgrid scale feature, and inclusion of some assumptions to overcome computation limitations make GCM results inconsistent to be used directly. Therefore, to have a more reliable description of the local-scale climate, downscaling of the outputs of GCMs is necessary. Statistical downscaling methods are mainly categorized into three groups: weather types, weather generators, and regression methods. Weather generators have a great advantage of being able to produce a large ensemble of projections on a daily scale in comparison to other downscaling methods (Wilby et al., 2004).

LARS-WG is a weather generator that is capable of simulating temperature and precipitation with a reasonable confidence in climate change condition, according to former studies (Lawless et al., 2005; Semenov and Doblas-Reyes, 2007; Semenov, 2009; Hashmi et al., 2011; Zarghami et al., 2011; King et al., 2012; Gohari et al., 2013; Kim et al., 2013; SeungHwan et al., 2013). In this study, it has been used to downscale GCMs and generate synthetic weather data in the real case study.

To simulate runoff in future climate change condition, hydrologic models are essential. In this study, climatic outputs of the downscaling model are considered as inputs for the rainfall-runoff model to be developed. Checking of the outputs of LARS-WG revealed a need for a nonlinear interpolator model. Two types of data-driven models are used to develop the rainfall-runoff relation because of the uncertainty. Artificial neural network (ANN) and an M5 model tree are selected to develop a rainfall-runoff model in the selected basin.

ANN is an accurate predictive tool that is able to detect complex nonlinear relationships. Over the last few decades, ANN has extensively been used to model the nonlinear relation between rainfall and runoff processes (Hsu et al., 1995; Anctill and Tape, 2004; Wu et al., 2010; Kisi et al., 2013). Because of a low correlation between monthly rainfall and runoff data, common approaches in data-driven modeling do not meet the accepted performance criteria. As a solution to this deficiency, Garbrecht (2006) developed an ANN model considering each calendar month that will be used in this study.

To not just lean on the ANN method, another data-driven method has also been used. An M5 model tree, a classification-regression model, is employed to discover the rainfall- runoff relation and its results are compared with those of ANN. By combining linear models following the methods of Becker and Kundzewicz (1987), to model nonlinearity of a flood routing problem, the idea of splitting a complex model into some linear problems was entered into water engineering. Afterward, the M5 regression technique was employed in water engineering by Solomatine and Dulal (2003), Bhattacharya and Solomatine (2005), Shrestha and Solomatine (2008), Solomatine and Shrestha (2009) and Singh et al. (2010).

During the last decade, wavelet transform (WT) has widely been used as a tool for analysis, decomposing, denoising, and compression of hydrological time series. Initially in hydrology, it has been used to analyze and compare the time series (Smith et al., 1998; Saco and Kumar, 2000; Brunsell, 2010; Labat, 2010; Mishra et al., 2011) and employed to denoise rainfall and runoff time series (Chou, 2011). Recently, WT has also been applied extensively to decompose hydrological time series to improve the performance of black-box hydrological models. Wang and Ding (2003) studied the application of WT in predicting daily stream-flow and monthly groundwater levels with a threelayer network and back propagation (BP) training method. WT is also used in conjunction with an ANN in stream-flow forecasting (Anctill and Tape, 2004; Kisi, 2009; Wang et al., 2009; Tiwari and Chatterje, 2010; Dhanya and Kumar, 2011; Nourani et al., 2011). Although none of the former studies integrated an M5 model tree and WT, it has been performed in this research.

To study the effects of runoff changes on the supply of water resources, simulation tools are needed. System dynamics (SD) is a mathematical modeling technique for analyzing and solving complex systems. It is used in different fields of water engineering, e.g., flood control, hydrological simulation, and climate change impacts assessments. In recent years, Simonovic et al. (1997) developed a model for simulating the Aswan High Dam to manage the Nile River basin. They used SD to allocate water for irrigation demands and understand the effect of other management scenarios in the region. Simonovic and Lanhai (2003) studied the impacts of climate change on a complex flood control system using SD for hydrological modeling and flood control system. Ahmad and Simonovic (2006) also used SD to simulate the operation of Shellmouth reservoir in Canada. SD is an important tool in the management of water resources and has also been used frequently for several cases in Iran (e.g., Salavitabar et al., 2006; Madani and Marino, 2009; Bagheri et al., 2010; Hassanzadeh et al., 2012; Zarghami and Akbariye, 2012).

The entire flowchart of the process is shown in Figure 1. Briefly, it consists of applying statistical downscaling methods for climate change studies. It then uses data-driven approaches for rainfall-runoff modeling, and reservoir operation is simulated by an SD model. This process has been applied successfully in a real case study and suggested for other cases, especially in arid and semiarid regions.

\section{Case Study}

Zolachay sub-basin in the northwest of Urmia Lake basin, 


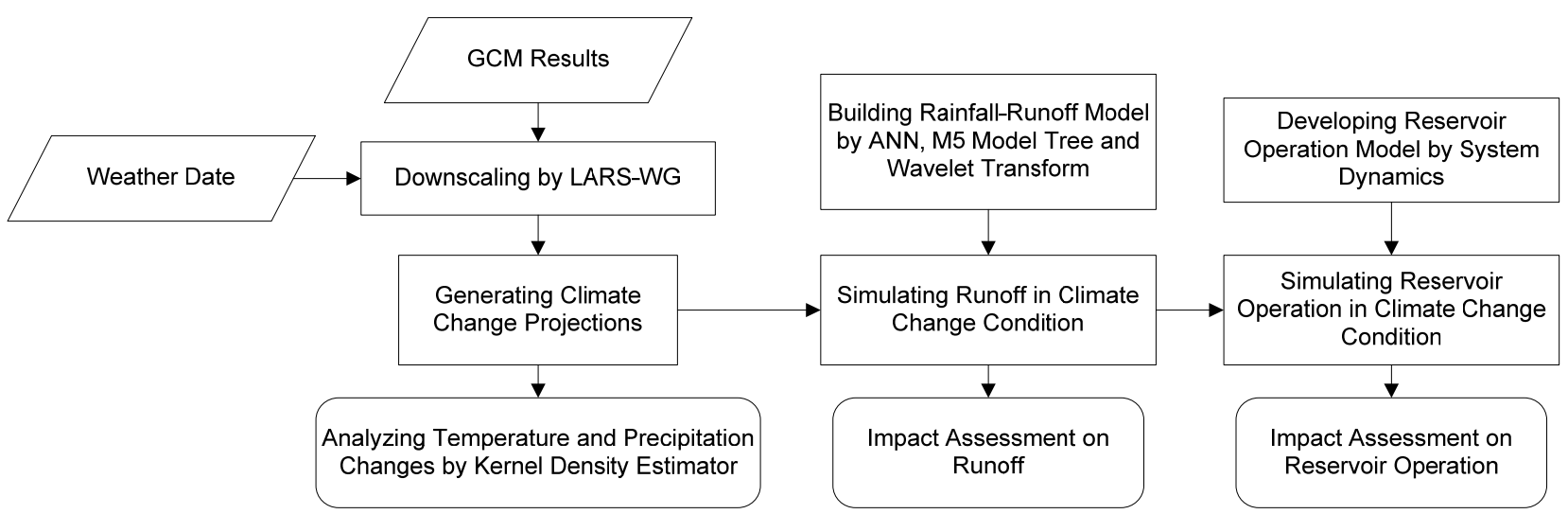

Figure 1. Flowchart of the study.

Iran, is located between $37^{\circ} 52^{\prime}$ and $38^{\circ} 24^{\prime}$ North latitude and between $44^{\circ} 13^{\prime}$ and $45^{\circ} 29^{\prime}$ East longitude. Salmas County with an area of $2,528 \mathrm{~km}^{2}$ is located in West Azerbaijan Province. Hydrologic borders of Zolachay coincide with the political borders of Salmas County (Figure 2). Zolachay River, which originates from mountains between Iran and Turkey and then flows into Urmia Lake, is the main river of this watershed with a length of $100 \mathrm{~km}$. Zola Dam constructed on Zolachay River meets the domestic water consumption needs of Salmas city and supplies irrigation water for about 17,400 hectares of agricultural fields. Salmas, with a population of more than 80,000 , is an important city in the province; however, its development is now threatened by water scarcity. This paper aims to investigate climate change, its impact on runoff in Zolachay, and finally the performance of Zola Reservoir.

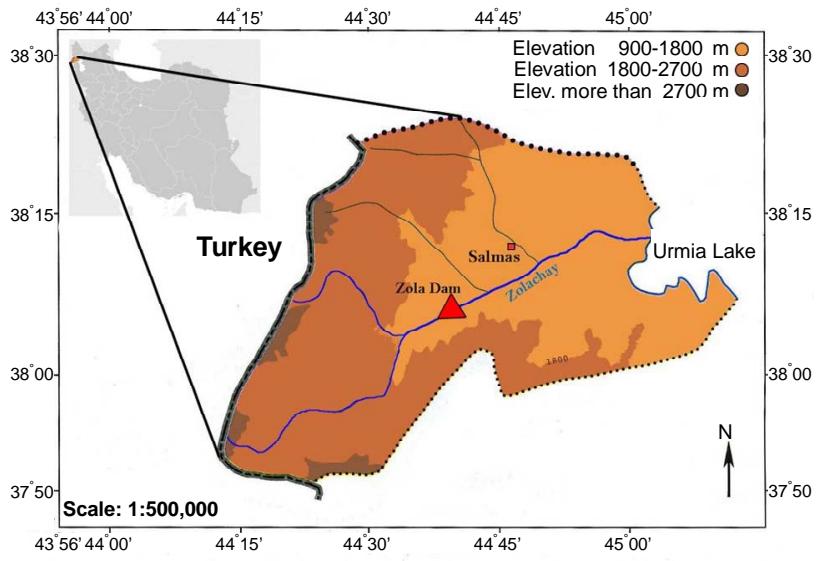

Figure 2. Topography of Zolchay basin and its position on Iran's map.

\section{Methodology}

This study aims to assess changes in precipitation and temperature in horizon 2020 for Zolachay by downscaling results of GCMs under three emission scenarios. To analyze the results of GCMs, a Kernel density estimator has been used to clarify the trend of changes in the region. Two data-driven methods in conjunction with WT have been used to develop a rainfall-runoff model appropriate for climate change study. A simulation model based on the SD approach has been developed to study the performance of Zola Reservoir. The general process is already shown in Figure 1, and the next subsections illustrate the detail of each method.

\subsection{Downscaling}

Weather generators as statistical downscaling methods are used in climate change impact projections (Semenov and Stratonovitch, 2010; Fatichi et al., 2011). LARS-WG (Semenov and Barrow, 2002) was first developed to generate stochastic weather data. It is capable of producing daily weather data and monthly climate change projections. LARS-WG 5.0 uses predictions of 15 GCMs approved by the IPCC (AR4) under three socioeconomic scenarios of SRES storylines of A1B, A2, and B1 (Arnell et al., 2004). However, for some GCMs, all the three emission scenarios are not available and the number of total combinations is 35 . Names and characteristics of the 15 GCMs used in this research are shown in Table 1.

LARS-WG determines the precipitation status for a given day, based on the length of wet and dry sequences chosen from a semiempirical distribution fitted to the observed data of a station (Semenov et al., 1998). Daily minimum and maximum temperatures are generated through stochastic processes, with daily means and standard deviations conditioned on the precipitation status of that day (Zhang et al., 2011). For determining calibration status, statistical characteristics (mean, standard deviation, and distributions) of observed and generated data can be compared by chisquared test, Student's $t$-test, and $F$-test. After calibrating the LARS-WG, future synthetic data are generated based on the results of GCMs. To meet the objectives of this research, generated daily data for the study period $(2011 \sim 2030)$ have been converted to a monthly scale. LARS-WG produces climatic time series for future periods by adjusting the $\Delta$-changes of monthly GCM predictions to a historical period for the grid covering the site (Semenov and Stratonovitch, 2010). 
Table 1. Information of the GCM Used in This Study (Adopted From Rothamsted Research, 2013)

\begin{tabular}{|c|c|c|c|c|c|}
\hline No. & Global Climate Model & Centre & Centre acronym & Country & Grid resolution \\
\hline 1 & CSIRO-MK3.0 (CSMK3) & $\begin{array}{l}\text { Australia's Commonwealth Scientific and } \\
\text { Industrial Research Organisation }\end{array}$ & CSIRO & Australia & $1.9^{\circ} \times 1.9^{\circ}$ \\
\hline 2 & CGCM3 (T47) (CGMR) & $\begin{array}{l}\text { Canadian Centre for Climate Modelling and } \\
\text { Analysis }\end{array}$ & CCCma & Canada & $2.8^{\circ} \times 2.8^{\circ}$ \\
\hline 3 & FGOALS-g1.0 (FGOALS) & Institute of Atmospheric Physics & LASG & China & $2.8^{\circ} \times 2.8^{\circ}$ \\
\hline 4 & CNRM-CM3 (CNC3M) & Centre National de Recherches Meteorologiques & CNRM & France & $1.9^{\circ} \times 1.9^{\circ}$ \\
\hline 5 & IPSL-CM4 (IPCM4) & Institute Pierre Simon Laplace & IPSL & France & $2.5^{\circ} \times 3.75^{\circ}$ \\
\hline 6 & ECHAM5-OM (MPEH5) & Max-Planck Institute for Meteorology & MPI-M & Germany & $1.9^{\circ} \times 1.9^{\circ}$ \\
\hline 7 & MIROC3.2 (hires) (MIHR) & Meteorological Research Institute, Japan & NIES & Japan & $1.1^{\circ} \times 1.1^{\circ}$ \\
\hline 8 & BCM2.0 & Bjerknes Centre for Climate Research & BCCR & Norway & $1.9^{\circ} \times 1.9^{\circ}$ \\
\hline 9 & INM-CM3.0 (INCM3) & Institute for Numerical Mathematics & INM & Russia & $4^{\circ} \times 5^{\circ}$ \\
\hline 10 & HadCM3 & UK Met. Office & UKMO & UK & $2.5^{\circ} \times 3.75^{\circ}$ \\
\hline 11 & HadGEM1 & & & & $1.3^{\circ} \times 1.9^{\circ}$ \\
\hline 12 & GFDL-CM2.1 (GFCM21) & Geophysical Fluid Dynamics Laboratory & GFDL & USA & $2.0^{\circ} \times 2.5^{\circ}$ \\
\hline 13 & GISS-AOM (GIAOM) & Goddard Institute for Space Studies & GISS & USA & $3^{\circ} \times 4^{\circ}$ \\
\hline 14 & PCM (NCPCM) & National Centre for Atmospheric Research & NCAR & USA & $2.8^{\circ} \times 2.8^{\circ}$ \\
\hline 15 & CCSM3 (NCCSM) & & & & $1.4^{\circ} \times 1.4^{\circ}$ \\
\hline
\end{tabular}

\subsection{Artificial Neural Network}

The ANN method is a parallel distributed informationprocessing system that resembles the biological neural network of human brain (Haykin, 1994). A three-layer network with one intermediate (hidden) layer is used in this study. Although multilayer networks can be employed, the study of Coulibaly et al. (2000) has shown that a single hidden layer can estimate any complex nonlinear function sufficiently. Levenberg-Marquardt algorithm (LMA), which is a gradient-descent method, is employed to train the network. This method is the most efficient one among gradient-based methods (Piotrowski and Napiorkowski, 2011). The purpose of the training algorithm is to minimize the total error of $E$ :

$e_{p}=y_{p}-\hat{y}_{p}$

$E=\frac{1}{2} \sum_{p=1}^{n}\left(e_{p}\right)^{2}$

where $e_{p}$ is the error of the network for pattern $p, n$ the number of patterns selected to train, $y_{p}$ the target value of the $p$ th pattern, and $\hat{y}_{p}$ the output value of network for the $p$ th pattern. According to the LMA training method, approximates are updated by the following equation:

$\hat{y}_{k+1}=\hat{y}_{k}-\left(J^{T} J+\mu I\right)^{-1} J^{T} e$

where $\hat{y}_{k+1}$ is an approximate for network in $k+1$ epoch, $J$ is the Jacobian matrix of partial derivations of the network with respect to the weights and biases, $e$ is a vector matrix of network errors, $I$ is the identity matrix, and $\mu$ is the learning rate where $0<\mu \leq 1$. In gradient-descent algorithms, $\mu$ is known as a step-size parameter. A high value of $\mu$ can oscillate the net- work about the true solution or diverge completely. In addition, the network will take a long time to converge to the solution by choosing a low value of $\mu$. In this study, the value of $\mu$ changes after each step according to the increase or decrease in the error value, and the selected values of $\mu$ are multiples of 0.07 , which is the initialized value of the step-size parameter to train a three-layer network with ten neurons in the middle.

\subsection{M5 Model Tree}

Despite its high performance, the M5 model tree technique is not a popular machine learning method in water engineering. This technique is able to solve high-dimensional complex problems fast and precisely. In addition, interpretability characteristics of an M5 model tree make it advantageous over other black-box data-driven methods such as ANN. A model tree splits data into subsets and uses multivariate linear regression fittings. In other words, model trees resolve complex models by dividing them into simple tasks and then combining their solutions. The M5 model tree employed in this paper follows the algorithm already presented by Quinlan (1992). The first step is to select an input variable for splitting and then to divide it. This divide-and-conquer method is based on searching the best split for the selected variable and finally treating it with formed subsets separately. To find the best split, the treated measure is the standard deviation reduction, $\Delta_{\text {error }}$, as follows:

$$
\Delta_{\text {error }}=\operatorname{sd}(T)-\sum_{i} \frac{\left|T_{i}\right|}{|T|} \operatorname{sd}\left(T_{i}\right)
$$

in which sd represents the standard deviation of a set, $T$ denotes a selected set of inputs, and $T_{i}$ is a divided subset of $T$. After finding the best split, fitting a linear equation to each subset is the next step. 


\subsection{Wavelet Transform}

WT, a further development of Fourier transform, is an efficient tool to study stationary and nonstationary time series. WT has an ability to capture precisely low-frequency information using long time intervals and high-frequency information using shorter intervals (Mishra et al., 2011). Continuous WT is defined as the sum of the signals over the whole time, multiplied by a scaled, shifted version of the wavelet function $\psi(t)$. Equation (5) shows how a function $f(t)$ is decomposed:

$\gamma(s, \tau)=\int f(t) \psi_{s, \tau}^{*}(t) d t$

where $s$ is a scale parameter $(s>0), \tau$ a translation parameter $(\tau \in R)$, and * the complex conjunction. The inverse form of WT is wavelet expansion of equation (6). The wavelets generated from a single basic wavelet $\psi(t)$, called the mother wavelet, are calculated as shown in equation (7):

$f(t)=\iint \gamma(s, t) \psi_{s, \tau}(t) d \tau d s$

$\psi_{s, \tau}(t)=\frac{1}{\sqrt{s}} \psi\left(\frac{t-\tau}{s}\right)$

where $s^{-1 / 2}$ is called energy normalization. Because of redundancy and not having an analytical solution for many wavelets, using a continuous form of WT directly is not practical. Therefore, discrete WTs have been introduced to overcome these problems. Discrete WTs are stretched and translated into discrete steps. Equation (8) presents a continuous function called a discrete wavelet:

$\psi_{j, k}(t)=\frac{1}{\sqrt{s^{j}{ }_{0}}} \psi\left(\frac{t-k \tau_{0} s^{j}}{s^{j}{ }_{0}}\right)$

where $j$ and $k$ are integers, $s_{0}$ is a fixed dilation step $\left(s_{0}>0\right)$, and $\tau_{0}$ is a translation parameter. The relations $s_{0}=2$ and $\tau_{0}=1$ are usually attributed to dilation and translation parameters, respectively. However, it is necessary to emphasize that discrete WTs are not time discrete; they are discrete just in dilation and translation.

\subsection{System Dynamics}

Effective water management can be achieved using a comprehensive model. The SD approach with the capability of easy object-oriented programming has attracted a great deal of interest for integrated water resources management. In the context of SD, variables are stocks, flows, auxiliaries, or constants. The concept of SD is based on the interaction of stocks and flows and their feedbacks. Stocks are integrals, such as the amount of water in a reservoir. Generally, stock variables describe the state of a system and produce the information, based on which decisions and dealings are prepared, in advance. Flow variables define rates that can alter stock variables. The volume of a reservoir at any time can be computed as follows:

$$
\begin{aligned}
& V(t)=\int_{t_{0}}^{t_{n}}[Q(t)-\text { Regulated }(t)-\text { Evaporation }(t)-\operatorname{Spill}(t)] d t \\
& +V\left(t_{0}\right)
\end{aligned}
$$

where $V(t)$ is the reservoir volume, $Q(t)$ is the inflow to the reservoir, Regulated $(t)$ is the regulated water supplied to meet the demands, Evaporation $(t)$ represents evaporation from the reservoir, $\operatorname{Spill}(t)$ is the water spilled from the reservoir because of its limited capacity, and $V\left(t_{0}\right)$ is the initial reservoir volume.

Within the SD model, the Standard Operating Policy (SOP) is used to decide how much water can be allocated. In this approach, regulated water is considered equal to demands if:

$Q(t)+V(t)-$ Evaporation $(t)-$ Demand $(t)>V \min$.

Demands $(t)$ is the sum of demands and $V_{\min }$, a constant variable, is the minimum volume of the reservoir required to have an outflow. If the above condition is not satisfied, the regulated flow would be equal to:

$Q(t)+V(t)-$ Evaporation $(t)-V \min$

Figure 3 represents the stock-flow diagram developed for Zola Reservoir, and the model is then simulated using the VENSIM software.

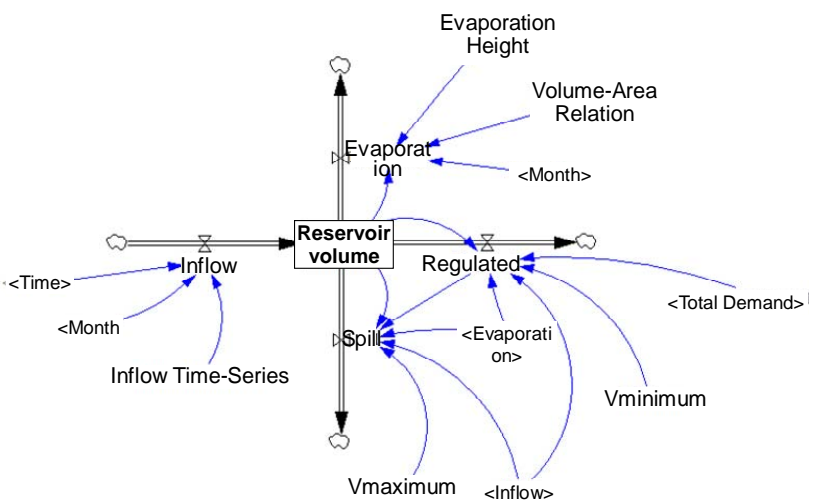

Figure 3. Stock-flow diagram for reservoir operation.

\section{Results}

The objective of this study is to find the changes in precipitation, temperature, and runoff in Zolachay basin. Then this study tries to simulate Zola Reservoir operation in future conditions. Hence, results of this study are presented in three subsections. The first subsection demonstrates the results of down- 

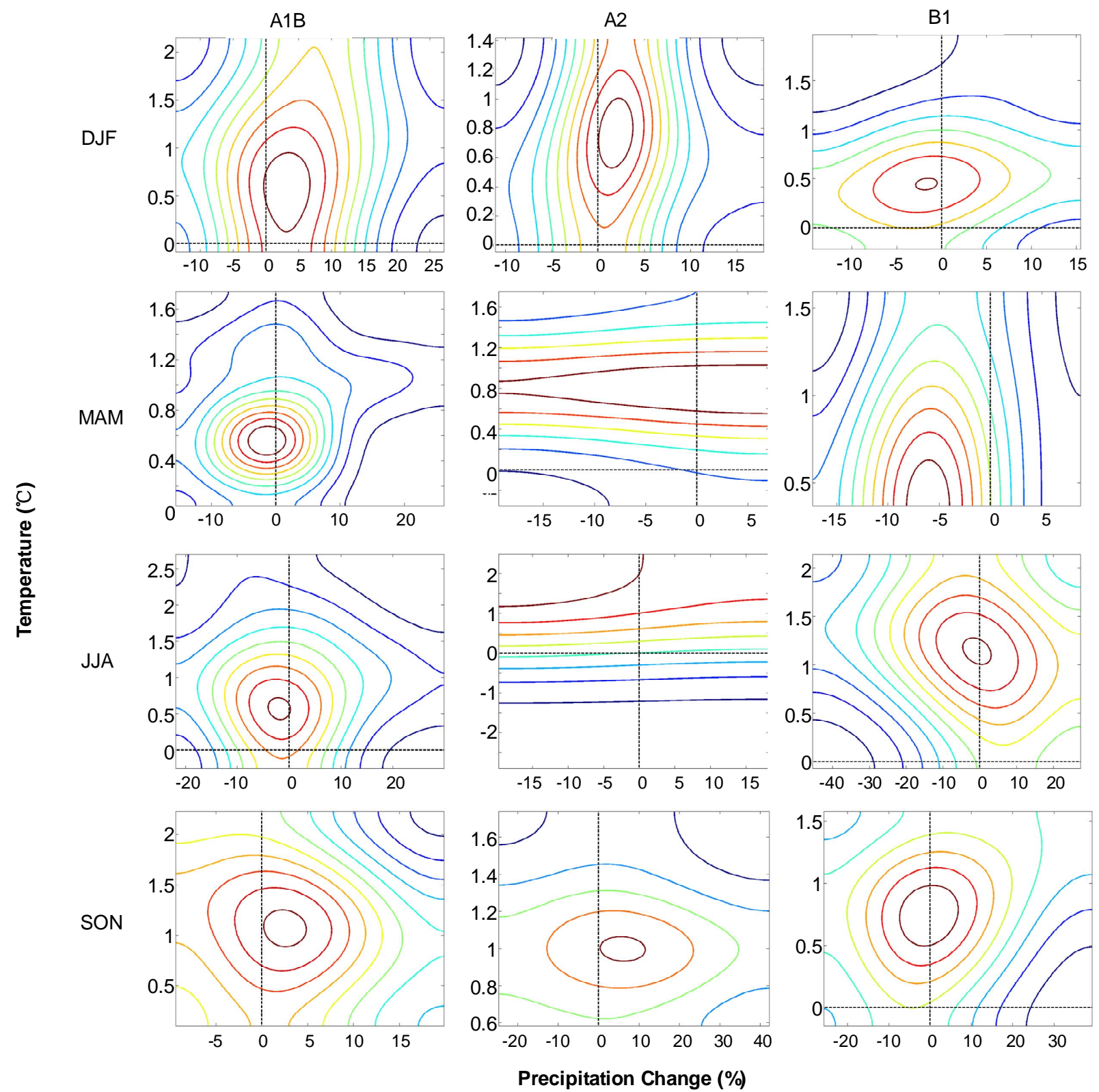

Figure 4. Density contours of predicted changes of precipitation versus temperature by using $15 \mathrm{GCMs}$ under three emission scenarios of A1B, A2 and B1 (2011 2030).

scaling the climatic change, and the second subsection discusses the impacts of climate change on runoff using rainfallrunoff models. The performance of Zola Reservoir in different scenarios is discussed in the last subsection.

\subsection{Downscaling of Climatic Change}

Input variables of LARS-WG, used to analyze the probable future condition, are the daily precipitation and temperature data of $1968 \sim 2010$. For calibration and validation of LARS-WG, distributions of seasonal wet/dry series, daily precipitation, and minimum and maximum temperatures for observed and generated data are compared by $\chi^{2}$ statistics. In addition, $t$ - and $F$-test are used to determine whether two sets of observed and generated data are significantly different or not. Calibration step in LARS-WG determines only how well the model can perform in the chosen site, to determine whether or not it is suitable (Semenov and Barrow, 2002). In the calibration step, LARS-WG performed quite well in simulating the statistical characteristics of stations in Zolachay basin.

After calibration of LARS-WG, a validation step for picking proper random seed is necessary. For generating climate variables from distributions, a random number is needed and LARS-WG 5.0 provides six random seeds. The same process and tests are used in the calibration step to evaluate perfor- 
mances of LARS-WG with random seeds. Comparing results, a random seed of 3571 was chosen to generate climate data.

Differences in the results of GCMs make it impossible for researchers to rely on the change values. Hence, dealing with a probability function of changes or an aggregation of results is recommended to assess the changes. In this paper, for revealing the condition that is more likely to occur, the Kernel density estimator is employed to estimate the probability of temperature and precipitation changes using 15 GCMs. Concentration of lines shows more probable changes. Density plots for $\mathrm{A} 1 \mathrm{~B}, \mathrm{~A} 2$, and $\mathrm{B} 1$ scenarios in four time periods of December-January-February (DJF), March-April-May (MAM), June-July-August (JJA), and September-October-November $(\mathrm{SON})$ are shown in Figure 4. A brief discussion on the results is as follows:

DJF: Changing to a warmer and wetter climate for A1B and $\mathrm{A} 2$ scenarios is more probable. However, GCM predicttions show a drier climate under the $\mathrm{B} 1$ scenario.

JJA: Drier and warmer climate is more likely to occur under A1B scenario. Predictions of GCMs under A2 scenario do not reveal a uniform tendency to a specific change. Although an increase in temperature is more probable, change in precipitation is not considerable under B1 scenario.

MAM: A warmer climate is expected for this season under all three scenarios. Precipitation change in A1B scenario is not important. For A2 and B1 scenarios, a tendency toward increasing precipitation is predicted.

SON: The basin is expected to experience a warmer and wetter climate in A1B and A2 scenarios. In addition, precipitation value will not experience a significant change under B1 scenario.

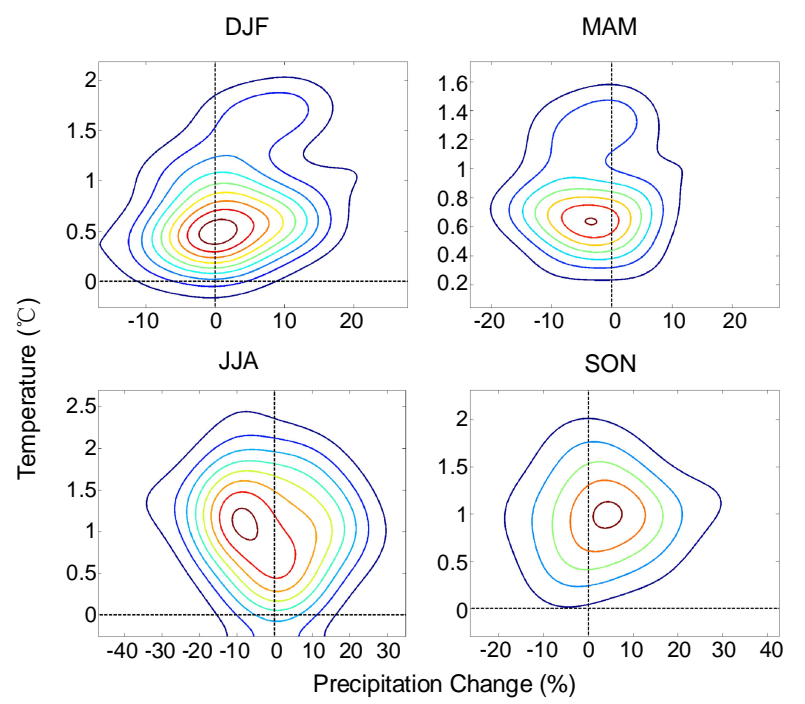

Figure 5. Density contours of predicted changes of precipitation versus temperature by 35 different combinations of projections (2011 2030).

Kernel density contours provides an assessment of a more likely condition. Figure 5 illustrates density lines for 35 combinations of different GCMs and emission scenarios (available in LARS-WG 5.0) in four periods of DJF, MAM, JJA, and SON. In Figure 5, an obvious warming tendency is shown for all four seasons. In DJF, precipitation change is likely not to be significant. According to the results shown in Figure 5, seasons of MAM and JJA are more probable to be drier in 2011 2030. In addition, precipitation changes are expected to be more positive in SON. In Figure 5, inner density contour lines contain the area with the most probability density. The center of this area shows the changes with the maximum probability, determined by a Kernel density estimator, and the results are summarized in Table 2.

Table 2. Predicted Average Changes of Precipitation and Temperature in the Year 2020

\begin{tabular}{lll}
\hline & Temperature Change $\left({ }^{\circ} \mathrm{C}\right)$ & Precipitation Change $(\%)$ \\
\hline DJF & 1.00 & 0 \\
MAM & 0.65 & -4 \\
JJA & 1.20 & -9 \\
SNO & 1.00 & 5 \\
\hline
\end{tabular}

Observational data on annual precipitation $(\mathrm{mm})$ and climate change projections are plotted in Figure 6. Potential of changes contain the domains of minimum and maximum precipitation values in all 35 climate change projections.

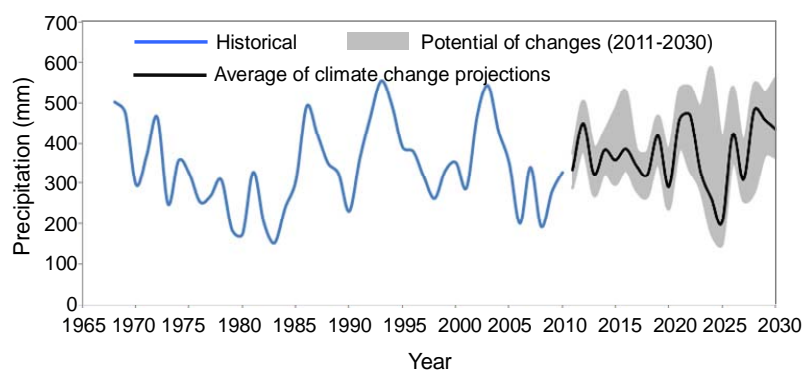

Figure 6. Annual precipitation of observed data (1968 2010) and potential of changes (2011 2030).

\subsection{Runoff}

Designs applied to the rainfall-runoff model in the case of ANN and M5 model tree approaches are different. To elaborate this issue, this section includes two parts: the first part discusses the results of hybrid models and the second part describes the assessment of climate impacts on runoff.

Performance of hybrid wavelet models depends on the function employed to decompose time series. Haar mother WT is employed to decompose inputs as follows:

$g(t)=\left\{\begin{array}{cc}1 & 0 \leq t<0.5 \\ -1 & 0.5 \leq t<1 \\ 0 & \text { otherwise }\end{array}\right.$

Haar transform is highly recommended to be used in rain- 
Table 3. The Proposed Rainfall-Runoff Models

\begin{tabular}{ll}
\hline Design & Combination of inputs \\
\hline Design 1 & $Q(t)=f(P(t), \operatorname{Tmin}(t), \operatorname{Tmax}(t))$ \\
Design 2 & $Q(t)=f(P(t), P(t-1), \operatorname{Tmin}(t), \operatorname{Tmax}(t))$ \\
Design 3 & $Q(t)=f(P(t), P(t-1), P(t-2), \operatorname{Tmin}(t), \operatorname{Tmax}(t))$ \\
Design 4 & $Q(t)=f(P(t), P(t-1), P(t-2), P(t-3), \operatorname{Tmin}(t), \operatorname{Tmax}(t))$ \\
\hline
\end{tabular}

Table 4. Performances of Data-Driven Models

\begin{tabular}{|c|c|c|c|c|c|c|c|c|c|c|}
\hline & & & \multicolumn{8}{|c|}{ Time Series Modeling Approach } \\
\hline & & & \multicolumn{2}{|c|}{ Design 1} & \multicolumn{2}{|c|}{ Design 2} & \multicolumn{2}{|c|}{ Design 3} & \multicolumn{2}{|c|}{ Design 4} \\
\hline & & & Train & Test & Train & Test & Train & Test & Train & Test \\
\hline \multirow{4}{*}{$\begin{array}{l}\text { Without } \\
\text { Wavelet }\end{array}$} & ANN & $\mathrm{R}^{2}$ & 0.45 & 0.27 & 0.50 & 0.28 & 0.57 & 0.53 & 0.69 & 0.44 \\
\hline & & RMSE & 3.162 & 3.606 & 2.955 & 3.742 & 2.775 & 3.873 & 2.559 & 2.264 \\
\hline & M5 & $\mathrm{R}^{2}$ & 0.56 & 0.44 & 0.62 & 0.53 & 0.65 & 0.53 & 0.77 & 0.70 \\
\hline & & RMSE & 2.749 & 2.847 & 2.572 & 2.637 & 2.477 & 2.536 & 1.998 & 2.057 \\
\hline \multirow{7}{*}{$\begin{array}{l}\text { With } \\
\text { Wavelet }\end{array}$} & ANN & $\mathrm{R}^{2}$ & 0.66 & 0.28 & 0.68 & 0.30 & 0.88 & 0.31 & 0.67 & 0.56 \\
\hline & & RMSE & 2.319 & 2.490 & 2.500 & 4.183 & 1.036 & 4.950 & 2.613 & 2.915 \\
\hline & M5 & $\mathrm{R}^{2}$ & 0.79 & 0.64 & 0.83 & 0.74 & 0.81 & 0.80 & 0.89 & 0.84 \\
\hline & & RMSE & 1.895 & 1.564 & 1.710 & 1.002 & 1.819 & 1.548 & 1.470 & 1.391 \\
\hline & & & \multicolumn{8}{|c|}{ Calendar Month Modeling Approach } \\
\hline & & & \multicolumn{2}{|c|}{ Design 1} & \multicolumn{2}{|c|}{ Design 2} & \multicolumn{2}{|c|}{ Design 3} & \multicolumn{2}{|c|}{ Design 4} \\
\hline & & & Train & Test & Train & Test & Train & Test & Train & Test \\
\hline \multirow{4}{*}{$\begin{array}{l}\text { Without } \\
\text { Wavelet }\end{array}$} & ANN & $\mathrm{R}^{2}$ & 0.62 & 0.59 & 0.71 & 0.62 & 0.80 & 0.80 & 0.89 & 0.82 \\
\hline & & RMSE & 2.212 & 2.189 & 1.624 & 2.115 & 1.255 & 1.143 & 0.966 & 1.416 \\
\hline & M5 & $\mathrm{R}^{2}$ & 0.71 & 0.70 & 0.83 & 0.79 & 0.88 & 0.86 & 0.93 & 0.92 \\
\hline & & RMSE & 1.885 & 1.915 & 1.455 & 1.580 & 1.248 & 1.323 & 1.060 & 1.094 \\
\hline \multirow{4}{*}{$\begin{array}{l}\text { With } \\
\text { Wavelet }\end{array}$} & ANN & $\mathrm{R}^{2}$ & 0.65 & 0.98 & 0.89 & 0.89 & 0.95 & 0.95 & 0.99 & 0.98 \\
\hline & & RMSE & 2.110 & 0.735 & 0.968 & 1.094 & 0.705 & 0.563 & 0.570 & 0.801 \\
\hline & M5 & $\mathrm{R}^{2}$ & 0.81 & 0.80 & 0.85 & 0.86 & 0.89 & 0.81 & 0.96 & 0.89 \\
\hline & & RMSE & 1.503 & 1.417 & 1.093 & 1.218 & 0.931 & 1.087 & 0.732 & 1.141 \\
\hline
\end{tabular}

fall-runoff modeling because it is similar to the signal and can capture signal features, especially peak values (Nourani et al., 2009). To evaluate the performance of the rainfall-runoff models, $R^{2}$ and RMSE measures are used:

$$
R^{2}=1-\frac{\sum_{i=1}^{n}\left(Q_{i}-\hat{Q}_{i}\right)^{2}}{\sum_{i=1}^{n}\left(\hat{Q}_{i}-\bar{Q}_{i}\right)^{2}}
$$

$R M S E=\sqrt{\frac{\sum^{n}\left(Q_{i}-\bar{Q}_{i}\right)^{2}}{n}}$

Here $Q_{i}$ is the observed value and $\hat{Q}_{i}$ the simulated value of stream-flow in the $i$ th time step. $\bar{Q}_{i}$ is the average of observed values.

\subsubsection{Hybrid Models}

One of the main challenges of rainfall-runoff modeling applied in climate change studies is its nonpredictable initial condition. High performances of many black-box rainfall-runoff models are attained using the flow of a previous time step as an input. Since the future stream-flow is unknown, this type of an assumption would increase the uncertainty. Hence, a model that is independent of the initial condition is preferred. For this reason, a model with just boundary conditions as inputs is ideal. In this study, variables of climate change projections represent the boundary conditions of the rainfall-runoff model.

In this circumstance, different designs and approaches of modeling are tested to assess the best rainfall-runoff model. Two modeling approaches and four designs (combination of inputs) have been tested in this study. Time-series modeling and calendar month modeling are the modeling approaches examined for monthly rainfall-runoff process. Each combination of inputs is presented in Table 3. Due to sensitivity of runoff changes to temperature (Tang and Lettenmaier, 2012), minimum and maximum temperatures are considered as inputs in rainfall-runoff modeling.

In Table 3, $Q(t)$ is the runoff in month $t, P(t)$ is the precipitation in month $t, T \min (t)$ is the average minimum tempera- 
ture, and $T \max (t)$ is the average maximum temperature in month $t$.

To make models more robust, precipitation inputs are decomposed by Haar wavelet function level 3. Results of each model and design with and without wavelet conjunction are summarized in Table 4 . To verify models, $25 \%$ of available data are used to test them. Performances of models are measured by $R^{2}$ and RMSE, as shown in Table 4. According to Table 4 , Design 4 has the best performance among all designs. Table 4 reveals the calendar month modeling approach provides a better performance. Also, impacts of wavelet decomposing on performances are obvious in Table 4 . The best performance belongs to the conjunction of wavelet and ANN in Design 4 of calendar month modeling.

\subsubsection{Runoff Impact Assessment}

Dealing with a large ensemble of climate change projections may confuse decision makers about the right approach. Hence, dealing with a simple or weighted average of projections to assess the risk of changes is recommended. In this study, simple averaging of projections has been selected to consider the ensemble of all projections. To determine the impacts of climate change on discharges in Zolachay Dam station, monthly runoff in $2011 \sim 2030$ has been simulated by outputs of LARS-WG (climate change projections) and a rainfall-runoff model developed (selected in previous subsection, wavelet-ANN in Design 4 of calendar month modeling). For a better presentation, historical hydrograph and simulated hydrographs in A1B, A2, and B1 scenarios are all plotted in Figure 7.
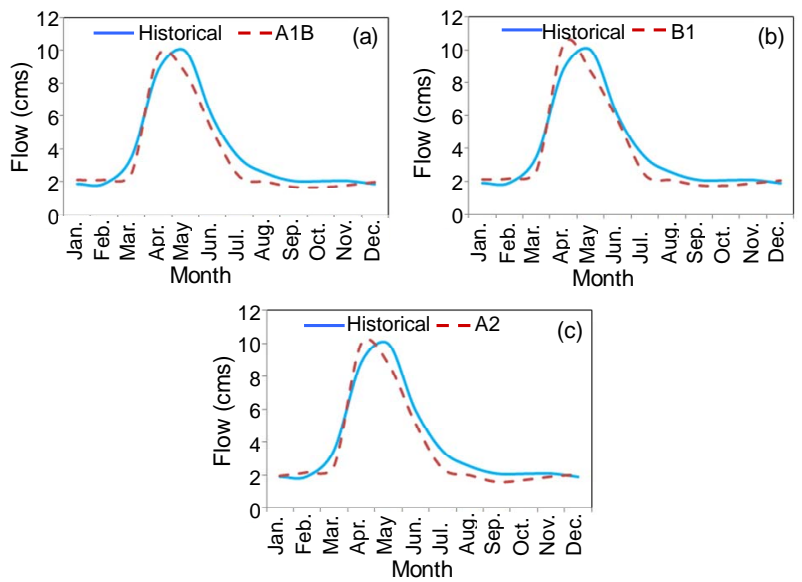

Figure 7. The predicted inflow to Zola reservoir (2011 2030) in three different emission scenarios with ensemble of the results of 15 GCMs by simple averaging.

In climate change condition, the peak of hydrographs has been shown to be transferred from May to April. Also, hydrographs in climate change condition are thinner, meaning a decrease in the annual runoff. The annual runoff in Zola Dam site is now approximately 3.84 cubic meters per second (cms), which is expected to be reduced to $3.47 \mathrm{cms}$ in $\mathrm{A} 1 \mathrm{~B}, 3.53 \mathrm{cms}$ in $\mathrm{A} 2$, and $3.62 \mathrm{cms}$ in $\mathrm{B} 1$ scenarios. The annual volume of these expected changes varies between 6.8 and 11.5 million cubic meters (MCM), which are high for the semiarid basin of Zolachay.

\subsection{Reservoir}

Zola Reservoir now supplies about $10 \mathrm{MCM}$ of domestic demands of Salmas city. Agricultural water demand for approximately 18,000 hectares is also satisfied by regulating water from the reservoir and by groundwater. Permissible limit of groundwater extraction is approximately $150 \mathrm{MCM}$. Based on the development plans, the domestic water need would increase to $13 \mathrm{MCM}$ and cultivation area to 30,000 hectares in 2020. Hence, studying the impact of temporal and quantitative changes of river runoff is essential. Moreover, the modified Tennant (Montana) method (Tennant, 1976), approved by the Ministry of Energy in Iran, is used to determine the environmental need of the river and its surrounding ecology. To study the performance of the system in meeting the demands, reliability and deficiency measures are selected. Reliability measure of a reservoir, $\alpha_{p}$, is defined as follows:

$\alpha_{p}=\frac{\text { Number of time periods such that }\left(X_{S} \geq \frac{P \times X_{D}}{100}\right)}{n}$

where $X_{S}$ is the amount of water supply, $X_{D}$ is the amount of demand, $P$ represents the percentage of reliability selected to study, and $n$ is the number of time steps where demand is not equal to zero.

Deficiency states the percent of water shortage in supplying demands:

Deficiency $=\frac{\text { Average volume of not delivered demands }}{\text { Average volume of demands }} \times 100$

Performance measures are calculated, under existing and development conditions, using the projected inflows obtained in the last subsection and the results are summarized in Table 5. From Table 5, it is evident that flows under climate change conditions can meet the existing demands well. However, in the development condition, this system is not able to meet agricultural demands fully. The volume of extraction from groundwater resources to irrigate cultivation areas is shown in Table 6.

Impact of climate change on the average levels of Zola Reservoir under existing demands is plotted in Figure 8. Climate change has been shown to affect considerably the operation of the reservoir under existing demands. In climate change condition, the reservoir would reach its minimum level two months earlier. In case of development, the levels of Zola Reservoir under existing demands are depicted in Figure 9. 
Table 5. Measures of Reliability and Deficiency in Supplying Demands with the Average of Different Climate Change Scenarios

\begin{tabular}{|c|c|c|c|c|c|c|c|c|c|c|c|}
\hline & & \multicolumn{5}{|c|}{ Existing Demands } & \multicolumn{5}{|c|}{ Development Demands } \\
\hline & & \multicolumn{4}{|c|}{ Reliability } & \multirow{2}{*}{ Deficiency } & \multicolumn{4}{|c|}{ Reliability } & \multirow{2}{*}{ Deficiency } \\
\hline & & $100 \%$ & $90 \%$ & $80 \%$ & $70 \%$ & & $100 \%$ & $90 \%$ & $80 \%$ & $70 \%$ & \\
\hline \multirow[t]{3}{*}{ Historical } & Dom & 100 & 100 & 100 & 100 & 0.1 & 99 & 100 & 100 & 100 & 0.1 \\
\hline & Env & 94 & 95 & 96 & 97 & 1.8 & 93 & 93 & 96 & 96 & 2.7 \\
\hline & Agr & 91 & 99 & 99 & 100 & 0.4 & 73 & 74 & 74 & 78 & 26.0 \\
\hline \multirow[t]{3}{*}{ A1B } & Dom & 98 & 98 & 98 & 98 & 2.2 & 98 & 98 & 98 & 98 & 0.9 \\
\hline & Env & 93 & 94 & 94 & 95 & 3.8 & 91 & 92 & 93 & 94 & 3.9 \\
\hline & Agr & 92 & 100 & 100 & 100 & 0.2 & 70 & 72 & 73 & 74 & 27.8 \\
\hline \multirow[t]{3}{*}{ A2 } & Dom & 98 & 98 & 98 & 97 & 3.0 & 98 & 98 & 98 & 98 & 1.7 \\
\hline & Env & 92 & 92 & 94 & 94 & 4.4 & 91 & 92 & 93 & 94 & 4.4 \\
\hline & Agr & 90 & 100 & 100 & 100 & 0.2 & 70 & 70 & 73 & 75 & 27.4 \\
\hline \multirow[t]{3}{*}{ B1 } & Dom & 97 & 98 & 98 & 98 & 2.1 & 98 & 98 & 98 & 98 & 1.0 \\
\hline & Env & 94 & 94 & 94 & 95 & 3.9 & 93 & 93 & 93 & 94 & 3.7 \\
\hline & Agr & 91 & 100 & 100 & 100 & 0.1 & 70 & 71 & 73 & 77 & 26.9 \\
\hline
\end{tabular}

* Dom: domestic demand; Env: Environmental demands; Agr: Agricultural demands.

Table 6. Future Groundwater Demand in Different Climate and Development Scenarios (MCM/Y)

\begin{tabular}{lllll}
\hline & Historical & A1B & A2 & B1 \\
\hline Existing condition & 110 & 124 & 122 & 120 \\
Development condition & 150 & 151 & 151 & 150 \\
\hline
\end{tabular}

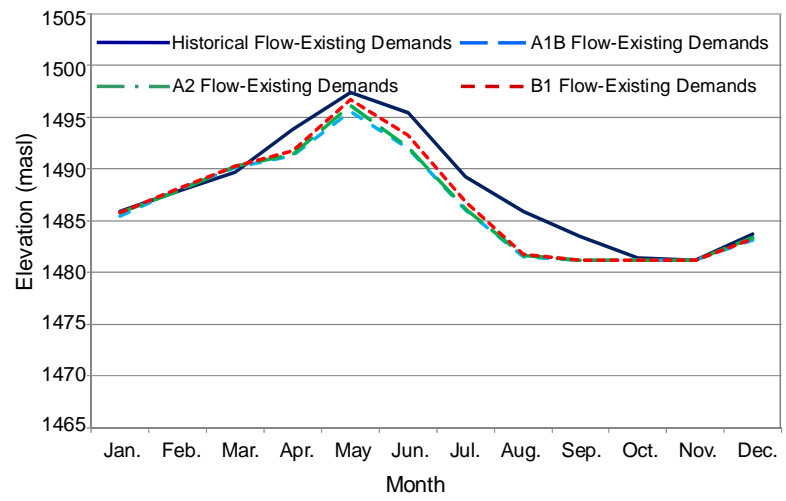

Figure 8. Average water level in reservoir (inflow in different climate change conditions and demands in the case of non-development in the basin).

Climate change has been shown to affect considerably the operation of Zola Reservoir in existing and development scenarios. If the development plan is implemented, in climate change condition, Zolachay will be able to satisfy domestic needs with a reliability of about $95 \%$ and environmental needs with about $90 \%$ reliability, which are satisfactory. In addition, the reliability of supplying agricultural demand is $70 \%$, which is fair. Irrigating 30,000 hectares of areas increases the dependency on groundwater in this basin, while its water table is continuously falling.

Hence, change in crop pattern as a nonstructural alternative and utilization of surface resources in the basin considering the condition of Urmia Lake can compensate for the shor-

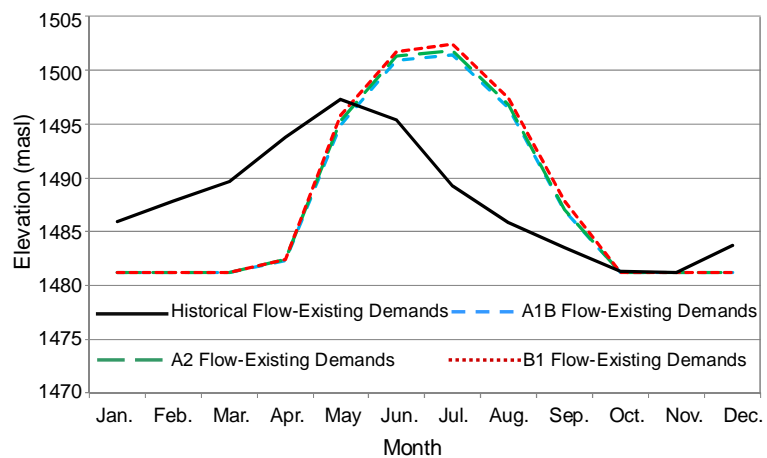

Figure 9. Average water level in reservoir (inflow in different climate change conditions and demands in the case of development in the basin).

tages in satisfying agricultural demand. In addition, because of climate change, a revision in the rule curve for Zola Reservoir operation is crucial. A comprehensive study on optimization of the reservoir operation to adapt to the extreme events (floods and droughts) due to climate change is also needed.

\section{Conclusions}

Downscaling the results of GCMs using a Kernel density function estimator has revealed that the Zolachay basin would have a warmer climate in horizon 2020. An analysis of seasonal changes shows that although annual precipitation in this watershed is expected to decrease, precipitation in fall season will rise. Simulating runoff in climate change condition reveals that, in all three emission scenarios, the inflow will decrease and the peak of the monthly hydrographs will experience a temporal change. The proposed methodology presented successfully the impacts of the climate change on operation of Zola Reservoir in existing and development conditions. According to the results, the reliability of water supply will decrease and its deficiency will increase, which shows the need for adapta- 
tion strategies in the Urmia Lake basin.

Acknowledgments. The authors are very grateful for the valuable comments of the editor-in-chief and also the respectful reviewers.

\section{References}

Abbaspour, K.C., Faramarzi, M., Ghasemi, S.S., and Yang, H. (2009). Assessing the impacts of climate change on water resources in Iran. Water Resour. Res., 45(10), W10434. http://dx.doi.org/10.1029/200 8WR007615

Abbaspour, M., Javid, A.H., Mirbagheri, S.A., Givi, F.A., and Moghi$\mathrm{mi}, \mathrm{P}$. (2012). Investigation of lake drying attributed to climate change. Int. J. Environ. Sci. Technol. 9(2), 257-266. http://dx.doi.org/ 10.1007/s13762-012-0031-0

Ahmad, S., and Simonovic, S.P. (2006). An intelligent decision support system for management of floods. Water Resour. Manage., 20(3), 391-410. http://dx.doi.org/10.1007/s11269-006-0326-3

Amir Rahmani, M., and Zarghami, M. (2013). A new approach to combine climate change projections by ordered weighting averaging operator; Applications to Northwestern Provinces of Iran. Global Planet. Change., 102, 41-50. http://dx.doi.org/10.1016/j.gloplacha. 2013.01.007

Anctill, F., and Tape, D.G. (2004). An exploration of artificial neural network rainfall-runoff forecasting combined with wavelet decomposition. J. Environ. Eng. Sci., 3(1), 121-128. http://dx.doi.org/10. 1139/s03-071

Ardakanian, R. (2005). Overview of water management in Iran. In: Water Conservation, Reuse, and Recycling: Proceeding of an Iranian American workshop, National Academies Press, Washiongton D.C, 18-33.

Arnell, N.W., Livermore, M.J.L., Kovats, S., Levy, P.E., Nicholls, R., Parry, M.L., and Gaffin, S.R. (2004). Climate and socio-economic scenarios for global-scale climate change impacts assessments Characterizing the SRES storylines. Global Environ. Change., 14(1), 3-20. http://dx.doi.org/10.1016/j.gloenvcha.2003.10.004

Bagheri, A., Darijani, M., Asgary, A., and Morid, S. (2010). Crisis in urban water systems during the reconstruction period: A system dynamics analysis of alternative policies after the 2003 earthquake in Bam-Iran. Water Resour. Manage., 24(11), 2567-2596. http://dx. doi.org/10.1007/s11269-009-9568-1

Barron, O., Silberstein, S., Ali, R., Donohue, R., McFarlane, D.J., Davies, P., Hodgson, G., Smart, N., and Donn, M. (2012). Climate change effects on water-dependent ecosystems in south-western Australia. J. Hydrol., 434-435, 95-109 http://dx.doi.org/10.1016/ j.jhydrol.2012.02.028

Bates, B.C., Kundzewicz, Z.W., Wu, S., and Palutikof, J.P. (2008). Climate change and water. Technical Paper of the Intergovernmental Panel on Climate Change, IPCC Secretariat, Geneva.

Becker, A., and Kundzewicz, Z.W. (1987). Nonlinear flood routing with multilinear models. Water Resour. Res., 23(6), 1043-1048. http://dx.doi.org/10.1029/WR023i006p01043

Bekele, E.G., and Knap, H.V. (2010). Watershed modeling to assessing impacts of potential climate change on water supply availability. Water Resour. Manage., 24(13), 3299-3320. http://dx.doi.org/10. 1007/s11269-010-9607-y

Beyene, T., Lettenmaier, D.P., and Kabat, P. (2010). Hydrologic impacts of climate change on the Nile River Basin: Implications of the 2007 IPCC scenario. Clim. Change, 100(3-4), 433-461. http:// dx.doi.org/10.1007/s10584-009-9693-0

Bhattacharya, B., and Solomatine, D.P. (2005). Neural networks and M5 model trees in modelling water level-discharge relationship.
Neurocomputing, 63, 381-396. http://dx.doi.org/10.1016/j.neucom. 2004.04.016

Brunsell, N.A. (2010). A multiscale information theory approach to assess spatial-temporal variability of daily precipitation. J. Hydrol., 385(1-4), 165-172. http://dx.doi.org/10.1016/j.jhydrol.2010.02.016

Chou, C.M. (2011). A threshold based wavelet denoising method for hydrological data modeling. Water Resour. Manage., 25(7), 18091830. http://dx.doi.org/10.1007/s11269-011-9776-3

Coulibaly, P., Anctill, F., and Bobée, B. (2000). Daily reservoir inflow forecasting using artificial neural networks with stopped training approach. J. Hydrol., 230(3-4), 244-257. http://dx.doi.org/10.1016/ S0022-1694(00)00214-6

Dhanya, C.T., and Kumar, N. (2011). Predictive uncertainty of chaotic daily streamflow using ensemble wavelet networks approach. Water Resour. Res., 47(6), W06507. http://dx.doi.org/10.1029/2010 WR010173

Fatichi, S., Ivanov, V.Y., and Caporali, E. (2011). Simulation of future climate scenarios with a weather generator. Adv. Water Resour., 34(4), 448-467. http://dx.doi.org/10.1016/j.advwatres.2010.12.013

Garbrecht, J.D. (2006). Comparision of three alternative ANN design for monthly rainfall-runoff simulation. J. Hydrol. Eng., 11(5), 502505. http://dx.doi.org/10.1061/(ASCE)1084-0699(2006)11:5(502)

Gohari, A., Eslamian, S., Abedi-Koupaei, J., Bavani, A.M., Wang, D., and Madani. K. (2013). Climate change impacts on crop production in Iran's Zayandeh-Rud River Basin. Sci. Total Environ., 442, 405-419. http://dx.doi.org/10.1016/j.scitotenv.2012.10.029

Harma, K.J., Johnson, M.S., and Cohen, S.J. (2012). Future water supply and demand in the Okanagan Basin, British Columbia: A scenario-based analysis of multiple, interacting stressors. Water Resour. Manage., 26(3), 667-689. http://dx.doi.org/10.1007/s1126 9-011-9938-3

Hashmi, M.Z., Shamseldin, A.Y., and Melville, B.W. (2011). Comparison of SDSM and LARS-WG for simulation and downscaling of extreme precipitation events in a watershed. Stochastic Environ. Res. Risk Assess., 25(4), 475-484. http://dx.doi.org/10.1007/s0047 7-010-0416-x

Hassanzadeh, E., Zarghami, M., and Hassanzade, Y. (2012). Determining the main factors in declining the Urmia Lake level by using system dynamics modeling. Water Resour. Manage., 26(1), 129-145. http://dx.doi.org/10.1007/s11269-011-9909-8

Haykin, S. (1994). Neural networks: A comprehensive foundation. MacMillan, NewYork.

Hoekstra, A.Y., Mekonnen, M.M., Chapagain, A.K., Mathews, R.E., and Richter., B.D. (2012). Global monthly water scarcity: Blue water footprints versus blue water availability. PLoS One. 7(2), e32688. http://dx.doi.org/10.1371/journal.pone.0032688

Hsu, K., Hoshin, V.G., and Sorooshian, S. (1995). Artificial neural network modelling of the rainfall-runoff process. Water Resour. Res., 31(10), 2517-2530. http://dx.doi.org/10.1029/95WR01955

Kim, H.K., Parajuli, P.B., and Filip To. S.D. (2013). Assessing impacts of bioenergy crops and climate change on hydrometeorology in the Yazoo River Basin, Mississippi. Agric. For. Meteorol., 169, 61-73. http://dx.doi.org/10.1016/j.agrformet.2012.10.007

King, L.M., Irwin, S., Sarwar, R., McLeod, A.I., and Simonovic, S.P. (2012). The effects of climate change on extreme precipitation events in the Upper Thames River Basin: A comparison of downscaling approaches. Can. Water Resour. J., 37 (3), 253-274. http:// dx.doi.org/10.4296/cwrj2011-938

Kisi, O. (2009). Neural networks and wavelet conjunction model for intermittent streamflow forecasting. J. Hydrol. Eng., 14(8), 773782. http://dx.doi.org/10.1061/(ASCE)HE.1943-5584.0000053

Kisi, O., Shiri, J., and Tombul, M. (2013). Modeling rainfall-runoff process using soft computing techniques. Comput. Geosci., 51, 
108-117. http://dx.doi.org/10.1016/j.cageo.2012.07.001

Labat, D. (2010). Cross wavelet analyses of annual continental freshwater discharge and selected climate indices. J. Hydrol., 385(1-4), 269-278. http://dx.doi.org/10.1016/j.jhydrol.2010.02.029

Lawless, C., Semenov, M.A., and Jamieson, P.D. (2005). A wheat canopy model linking leaf area and phenology. Eur. J. Agron., 22(1), 19-32. http://dx.doi.org/10.1016/j.eja.2003.11.004

Madani, K., and Marino, M. (2009). A system dynamics analysis for managing Iran's Zayandeh-Rud river basin. Water Resour. Manage., 23(11), 2163-2187. http://dx.doi.org/10.1007/s11269-008-93 76-z

Mishra, A.K., Ozger, M., and Singh, V.P. (2011). Wet and dry spell analysis of Global Climate Model-generated precipitation using power laws and wavelet transforms. Stochastic Environ. Res. Risk Assess., 25(4), 517-535. http://dx.doi.org/10.1007/s00477-010-041 9-7

Montenegro, S., and Ragab, R. (2012). Impact of possible climate and land use changes in the semi arid regions: A case study from North Eastern Brazil. J. Hydrol., 434-435, 55-68. http://dx.doi.org/10.10 16/j.jhydrol.2012.02.036

Nourani, V., Komasi, M., and Mano, A. (2009). A multivariate ANNwavelet approach for rainfall-runoff modeling. Water Resour. Manage., 23(14), 2877-2894. http://dx.doi.org/10.1007/s11269-00 9-9414-5

Nourani, V., Kisi, O., and Komasi, M. (2011). Two hybrid artificial intelligence approaches for modeling of rainfall-runoff process. $J$. Hydrol., 402(1-2), 41-59. http://dx.doi.org/10.1016/j.jhydrol.2011. 03.002

Piotrowski, A.P., and Napiorkowski, J.J. (2011). Optimizing neural networks for river flow forecasting - evolutionary computation methods versus the Levenberg-Marquardt approach. J. Hydrol., 407(1-4), 12-27. http://dx.doi.org/10.1016/j.jhydrol.2011.06.019

Quinlan, J.R. (1992). Learning with continuous classes. Proceedings of 5th Australian Joint Conference on Artificial Intelligence, World Scientific, Singapore, 343-348.

Raje, D., and Mujumdar, P.P. (2010). Reservoir performance under uncertainty in hydrologic impacts of climate change. Adv. Water Resour., 33(3), 312-326. http://dx.doi.org/10.1016/j.advwatres. 2009.12.008

Rothamsted Research. http://www.rothamsted.ac.uk/mas-models/lars wg/GCMs.htm (accessed Mar 16, 2013)

Saco, P., and Kumar, P. (2000). Coherent modes in multiscale variability of streamflow over the United States. Water Resour. Res. 36(4), 1049-1067. http://dx.doi.org/10.1029/1999WR900345

Salavitabar, A., Zarghami, M., and Abrishamchi, A. (2006). System dynamic model in Tehran urban water management. Water Wastewater J., 17(3), 12-28.

Semenov, M.A., Brooks, R.J., Barrow, E.M., and Richardson, C.W. (1998). Comparison of the WGEN and LARS-WG stochastic weather generators for diverse climates. Clim. Res., 10(2), 95-107. http: //dx.doi.org/10.3354/cr010095

Semenov, A.M., and Barrow, E.M. (2002). LARS-WG, A stochastic weather generator for use in climate impact studies. User manual, version 3.0 http:/www.rotharnsted.ac.uk/mas-models/download/ LARS-WG-Manual.pdf.

Semenov, M.A., and Doblas-Reyes, F.J. (2007). Utility of dynamic seasonal weather forecasts in predicting crop yield. Clim. Res., 34(1), 71-81. http://dx.doi.org/10.3354/cr034071

Semenov, M.A. (2009). Impacts of climate change on wheat in England and Wales. J. R. Soc. Interface, 6(33), 343-350. http://dx.doi. org/10.1098/rsif.2008.0285

Semenov, M.A. and Stratonovitch, P. (2010). Use of multi-model ensembles from global climate models for assessment of climate change impacts. Clim. Res., 41(1), 1-14. http://dx.doi.org/10.3354/ cr00836

Seung-Hwan, Y., Jin-Yong, C., Sang-Hyun, L., Yun-Gyeong, O., and Koun. Y.D. (2013). Climate change impacts on water storage requirements of an agricultural reservoir considering changes in land use and rice growing season in Korea. Agric. Water Manage., 117, 43-54. http://dx.doi.org/10.1016/j.agwat.2012.10.023

Simonovic, S.P., Fahmy, H., and Elshorbaghy, A. (1997). The use of object oriented modeling for water resource planning in Egypt. Water Resour. Manage., 11(4), 243-261. http://dx.doi.org/10.1023/ A:1007988424353

Simonovic, S.P., and Lanhai, L. (2003). Methodology for Assessment of Climate Change Impacts on Large-Scale Flood Protection System. ASCE J. Water Res. Plann. Manage., 129(5), 361-371. http://dx.doi.org/10.1061/(ASCE)0733-9496(2003)129:5(361)

Singh, K.K., Pal, M., and Singh, V.P. (2010). Estimation of mean annual flood in Indian catchments using backpropagation neural network and M5 model tree. Water Resour. Manage., 24(10), 20072019. http://dx.doi.org/10.1007/s11269-009-9535-x

Smith, L.C., Turcotte, D.L., and Isacks, B.L. (1998). Stream flow characterization and feature detection using a discrete wavelet transform. Hydrol. Process., 12(2), 233-249. http://dx.doi.org/10. 1002/(SICI)1099-1085(199802)12:2<233::AID-HYP573>3.0.CO; 2-3

Shrestha, D.L., and Solomatine, D.P. (2008). Data-driven approaches for estimating uncertainty in rainfall-runoff modeling. Int. J. River Basin Manage., 6(2), 109-122. http://dx.doi.org/10.1080/15715124. 2008.9635341

Solomatine, D.P., and Dulal, K. (2003). Model trees as an alternative to neural networks in rainfall-runoff modeling. Hydrol. Sci. J., 48(3), 399-411. http://dx.doi.org/10.1623/hysj.48.3.399.45291

Solomatine, D.P., and Shrestha, D.L. (2009). A novel method to estimate model uncertainty using machine learning techniques. Water Resour. Res., 45(12), W00B11. http://dx.doi.org/10.1029/2008WR 006839

Setegn, S.G., Rayner, D., Melesse, A.M., Dargahi, B., and Srinivasan, R., (2011). Impact of climate change on the hydroclimatology of Lake Tana Basin, Ethiopia. Water Resour. Res., 47(4), W04511. http://dx.doi.org/10.1029/2010WR009248

Sterling, S.M., Ducharne, A., and Polcher, J. (2013). The impact of global land-cover change on the terrestrial water cycle. Nature Clim. Change. 3, 385-390, http://dx.doi.org/10.1038/nclimate1690

Tang, Q., and Lettenmaier, D.P. (2012). 21st century runoff sensitiveties of major global river basins. Geophys. Res. Lett., 39 (6), L064 03. http://dx.doi.org/10.1029/2011GL050834

Tennant, D.L. (1976). Instream flow regimens for fish, wildlife, recreation and related environmental resources. Fisheries, 1(4), 6-10. http://dx.doi.org/10.1577/1548-8446(1976)001<0006:IFRFFW $>2$. $0 . \mathrm{CO} ; 2$

Tiwari, M.K., and Chatterje, C. (2010). Development of an accurate and reliable hourly flood forecasting model using wavelet-bootstrap-ANN (WBANN) hybrid approach. J. Hydrol., 394(3-4), 458470. http://dx.doi.org/10.1016/j.jhydrol.2010.10.001

Vörösmarty, C.J., Green, O., Salisbury, J., and Lammers, R.B. (2000) Global water resources: Vulnerability from climate change and population growth. Science, 289(5477), 284-288. http://dx.doi.org/10. 1126/science.289.5477.284

Wagener, T., Sivapalan, M., Troch, P.A., McGlynn, B.L., Harman, C.J., Gupta, H.V., Kumar, P., Rao, P.S.C., Basu, N.B., and Wilson., J.S. (2010). The future of hydrology: An evolving science for a changing world. Water Resour. Res., 46(5), W05301. http://dx.doi. org/10.1029/2009WR008906

Wang, W., and Ding, S. (2003). Wavelet network model and its appli- 
cation to the predication of hydrology. Nature Sci., 1(1), 67-71.

Wang, W., Jin, J., and Li, Y. (2009). Prediction of inflow at three Gorges Dam in Yangtze River with wavelet network model. Water Resour. Manage., 23(13), 2791-2803. http://dx.doi.org/10.1007/s11 269-009-9409-2

Wilby, R.L., Charles, S.P., Zorita, E., Timbal, B., Whetton, P., and Mearns, L.O. (2004). Guidelines for use of climate scenarios developed from statistical downscaling methods. IPCC. ww.ipcc-data. org/guidelines/dgm_no2_v1_09_2004.pdf

Wu, C.L., Chau, K.W., and Fan, C. (2010). Prediction of rainfall time series using modular artificial neural networks coupled with datapreprocessing techniques. J. Hydrol., 389(1-2), 146-167. http://dx. doi.org/10.1016/j.jhydrol.2010.05.040
Zarghami, M., Abdi, A., Babaeian, I., Hassanzadeh, Y., and Kanani, R. (2011). Impacts of climate change on runoffs in East Azerbaijan Iran. Global Planet. Change, 78(3-4), 137-146. http://dx.doi.org/ 10.1016/j.gloplacha.2011.06.003

Zarghami, M., and Akbariye, S. (2012). System dynamic modeling for complex urban water systems: Application to the city of Tabriz, Iran. Resour. Conserv. Recycling, 60. 99-106. http://dx.doi.org/10. 1016/j.resconrec.2011.11.008

Zhang, H., Huang, G.H., Wang, D., and Zhang, X. (2011). Uncertainty assessment of climate change impacts on the hydrology of small prairie wetlands. J. Hydrol., 396 (1-2), 94-103. http://dx.doi.org/10. 1016/j.jhydrol.2010.10.037 